\title{
Highly selective and sensitive detection of benzene, toluene, and xylene using oxide semiconductors
}

\author{
Jong-Heun Lee ${ }^{1}$ \\ ${ }^{1}$ Department of Materials Science and Engineering, Korea University, Seoul 02841, Republic of Korea
}

\begin{abstract}
Metal oxide semiconductor gas sensors have been widely used to detect ethanol, propane, carbon monoxide, formaldehyde and methane for screening intoxicated drivers and alarming the presence of explosive/dangerous gases. In contrast, the selective and sensitive detection of harmful BTX (Benzene, Xylene, and Toluene) for monitoring indoor/outdoor air pollution using oxide semiconductor chemiresistors remains challenging because of their low reactivity. In this contribution, various new strategies to achieve selective detection of sub-ppm-level BTX gases will be presented. The key ideas are (1) the use of catalytically active sensing materials with tuned nanostructures, (2) synergistic combination of different catalytic materials, (3) the gas reforming of less reactive BTX gas into more active and smaller species using catalyst-loaded micro-reactors, and (4) the tuning of sensing reaction using bilayer sensor design. Various examples for selective and sensitive BTX sensing will be covered, which include $\mathrm{Pd}$-loaded $\mathrm{SnO}_{2}$ yolk-shell micro-reactors, $\mathrm{Cr}$-doped $\mathrm{NiO}$ hierarchical nanostructures, Cr-doped $\mathrm{Co}_{3} \mathrm{O}_{4}$ nanorods, $\mathrm{Pd}$-loaded $\mathrm{Co}_{3} \mathrm{O}_{4}$ hierarchical nanostructures, $\mathrm{NiO} / \mathrm{NiMoO}_{4}$ nanocomposite hierarchical spheres, $\mathrm{NiO} / \mathrm{NiWO}_{4}$ composite yolk-shell spheres, $\mathrm{Cr}_{2} \mathrm{O}_{3}-\mathrm{ZnCr}_{2} \mathrm{O}_{4}$ hetero-nanostructures, $\mathrm{Co}_{3} \mathrm{O}_{4}$ film with $\mathrm{SnO}_{2} / \mathrm{TiO}_{2}$ overlayer, and $\mathrm{Pd}-\mathrm{SnO}_{2}$ film with $\mathrm{Co}_{3} \mathrm{O}_{4}$ overlayer. The main focus will be placed on the elucidation of gas sensing mechanism in relation to the gas reactivity, catalytic activity of sensing/additive materials, gas reforming of analyte gas, and catalytic oxidation of interference gas.
\end{abstract}

Key words: BTX gases, oxide semiconductor gas sensor, selectivity, indoor air monitoring, catalytic material 